\title{
METHODS OF MODERN APPROACH TO THE PROCESS OF EDUCATION AND TRAINING. CLUSTER
}

\section{Dilnoza Abdurashidovna Mutalova}

Lecturer, Department Of Preschool Education, Chirchik State Pedagogical Institute, Tashkent Region, Uzbekistan

\section{ABSTRACT}

This article discusses the idea of one of the modern types of organization of the educational process in preschool education-educational clusters. Clusters are groups of objects that are interconnected and divided on a common basis. Cluster-(translated from english means "bud", "bundle") activates the mental activity of preschoolers: develops the ability to ask questions, highlight the main thing, compare, establish causal relationships, draw conclusions.

KEYWORDS:- "Cluster", “educational efficiency”, “objects”, “educational skills”, “adoration”, "imagination”, "intuition".

\section{INTRODUCTION}

One of the modern types of Organization of the educational process is educational clusters. However, before talking about the cluster in education, you need to understand the basic concept. A cluster is a group of objects that are interconnected and arranged on a common basis.

The cluster represents a combination of several homogeneous elements that can be considered as independent units with certain properties. Cluster (translated from english means "bud", "bundle") a combination of several identical elements objects .

This method is logical, because it helps to work with a large amount of data, it must be studied, the main thing is systematization and it is necessary to present it in a certain way. It can be used at the introductory or hype stage of the subject to systematize existing information and identify areas of inadequate information. At the stage of developing the content of the topic, the cluster will allow you to fix parts of the new data. At the stage of the conclusion (reflection), the concepts are grouped and a logical relationship is established between them.

The cluster fades the mental activity of children of preschool age: to ask questions, highlight the main thing, compare, build cause-effect relationships and develop the ability to draw conclusions.

The essence of the method is to distinguish the subject, semantic units and graphic schema in a certain order.

When working on clusters, the following rules should be followed:

1. Do not be afraid to write everything that comes to mind. Give freedom of imagination and intuition.

2. Continue to work until the time or ideas are over. 
CURRENT RESEARCH JOURNAL OF PEDAGOGICS 2(10): 78-85,

October 2021 DOI: https://doi.org/10.37547/pedagogics-crjp-02-10-15

ISSN 2767-3278

(C)2021 Master Journals

Crossref doi) $\mathrm{g}^{\prime}$ Google

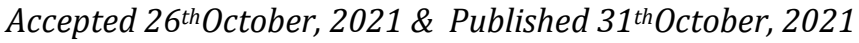

3. Try to build as many contacts as possible. Do not follow the pre-determined plan.

Sequence of actions when compiling a cluster:

Step 1-in the middle of a clean sheet is written a thought, a key word with a "heart" of the subject.

Step 2-all that is remembered about this topic around the word-expression of ideas, facts, images ("attack of the mind", the "chaos" model suitable for this topic)

3 stage-systematization is carried out. Chaotic records are combined into groups depending on the content that reflects a certain concept, reality.

4 stage-as noted, the words that appear are directly connected with the main concepts by lines, a new logical connection is established.

As a result, a structure that graphically reflects our thoughts, determines the information area of this topic.

Using cluster:

The cluster method can be used in the course of educational activities in the study of various subjects.

When using this method, the form of work can be absolutely any: individual, group and team. It is determined depending on the goals and tasks, the capabilities of the educator and the children's team. It is permissible to transfer one form to another. For example, this can be a personal business that creates its own cluster with each child. In the presence of new knowledge, based on personal drawings and taking into account the acquired knowledge, a general graphic scheme is drawn up as a joint discussion of the past material. The cluster can first be used as an individual job for organizing work during educational activities. Secondly, it is important that the educator has a certain experience in its preparation.
Advantages and results of the method

The use of cluster has the following advantages:

-it allows you to retrieve large amounts of data;

-all participants of the team are involved in the training process and this is very interesting;

-children will be active and open, because they are not afraid to make mistakes, they do not hesitate to make the wrong decision.

During this work, the following skills are formulated and developed:

-ability to ask questions;

-separation of the main thing;

-establish relationships and create conclusions;

-general understanding of the problem and passing through the general aspects;

- comparison and analysis;

-implementation of analogs.

How to use the cluster method for preschool children?

Cluster technique develops systemic thinking, teaches children to systematize not only educational material, but also their value judgments, teaches children to formulate and express their thoughts based on observations, experience and new knowledge, develops the ability to simultaneously consider several positions, creatively process information.

Educational activity using the cluster method allows preschoolers to express themselves, express their vision of the issue, and freedom of creative activity. In general, non-traditional technologies used in the educational process strengthen the motivation of pupils, form an atmosphere of cooperation and increase the selfesteem of children, give them a sense of creative 
CURRENT RESEARCH JOURNAL OF PEDAGOGICS 2(10): 78-85,

October 2021 DOI: https://doi.org/10.37547/pedagogics-crjp-02-10-15

ISSN 2767-3278

(C)2021 Master Journals

\section{Crossref doi) gr Google}

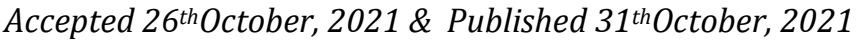

freedom.

Success in education and upbringing can be achieved only if it is interesting to children. Therefore, the educator must constantly look for new methods of education and training, be able to apply them in practice, accumulate and apply everything that can turn activity into joyful knowledge. Only the goal of the educator's activity, aimed at finding, assimilation and introduction of educational innovations, depends on how quickly changes will occur in his pedagogical activity.

Currently, teachers face global problems:ensuring the individual path of the child's development through the use of all types of activities provided for by state standards: educational, individual, constructive research, organizational and project. Educators need to look for new pedagogical technologies in the organization of the correctional and educational process of the formation of a personality with communicative competence. The child should be independent and relational in various types of activities-play, communication, cognitive research, project, etc.A preschool-age child is able to ask questions to adults and peers, show interest and interest in their interaction, try to independently explain the phenomena of nature and the actions of people; is prone to observation, experimentation..The word "Interactive" comes from the English word interact, move, search. Interactivity refers to the ability to communicate or interact in conversation mode, with something (for example, with a computer) or with a person (personality). Thus, interactive learning is an educational environment based on the interaction of children with learning, serving as an area of learning experience.

The essence of interactive education is that the learning process is organized in such a way that almost all educators are involved in the cognitive process, have the ability to understand and reflect on what they know and think. In the process of knowledge of preschool children, the educator makes his personal contribution to the joint activities in the mastering of educational materials, shares knowledge, ideas, methods of activity. In addition, this happens in an environment of goodwill and mutual support, which allows not only to acquire new knowledge, but also to develop cognitive activity, turning it into higher forms of cooperation.

Interactive methods

Mikrofon-this method of work, in which children together with the educator form a circle and imitate each other, or hand over a toy mikrofon, expresses their thoughts on a specific topic.

For example, a child takes a microphone, speaks about himself in several sentences and transmits the microphone to another child.All words of children are accepted, approved, but not discussed.

Discussion (debat) - method of work during which children are standing in an apartment, express their thoughts on a given subject, transfer the microphone to each other, but the statements are discussed: children btrish each other questions, answer them in search of a way to solve the problem.(For example, the Kamron has a bad mood, so children are offered ways to eliminate or eliminate the problem that affects the mood of the child).

Together-the type of method by which children form working pairs and perform the proposed task, for example, in turn, describes the picture.

Chain is a type of method by which children discuss tasks and present their proposals in a simulated chain. For example, they create a fairy tale based on a table, which is represented by a drawing or conditional characters in the drawing of a fairy tale. Another way to use this method: the first child calls an object, the second-its 
CURRENT RESEARCH JOURNAL OF PEDAGOGICS 2(10): 78-85,

October 2021 DOI: https://doi.org/10.37547/pedagogics-crjp-02-10-15

ISSN 2767-3278

(C)2021 Master Journals

\section{Crossref doi) 81 Google}

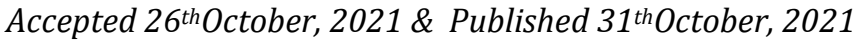

property, the third - an object with the same properties. For example, carrots-carrots sweetsweet sugar-white-white snow ... and so on.

Snowball is a method by which children join small groups and discuss a problematic issue or agree on a clear sequence of actions of each member of the group and perform a general task. For example, they become a team and build a house in which the order of each action is agreed in advance in order for this or that child to work in a sequential way.

Synthesis of ideas is a method in which children unite in small groups and perform a specific task, for example, drawing on paper.When the first group draws, it passes the drawing to another group, whose members perform the completed task. After the work is completed, they will draw a general history of what they drew and why they drew.

Horizons are interactive teaching methods when each child or each group performs a task, for example, composes a fairy tale in a new way, discusses it, and then offers suggestions or ideas (for example, how to finish a fairy tale so that the cuckoo survives; how to help the cuckoo deceive the fox, and the like).

A common project is a way of working in which children are grouped into several groups (34).Groups perform various tasks, each of which is aimed at solving a certain aspect of the task, for example, they draw their favorite characters and talk about them. Each group presents its own "project" - the collective work "beloved kahram" and its joint discussion.

Associative Flower (Association) is a method in which children are united into several groups to solve a common task: reflect a certain concept, such as "middle" of a flower, for example, "toys", "flowers", "fruits", "animals".tiradiEach group chooses word combinations or pictureassociations that are glued around this association. The team that makes the largest flower wins(the most chosen pictureassociations or words-with associations).

"Decision tree" - a method of work, which includes several stages:

1. For example, quot; What do you need a tree for happiness?.

2.To consider the scheme in which the gri is a rectangle "trunk" (this indicates the problem), straight lines - "branches" (ways to solve it) and circles - "leaves" (solve the problem).

3. Problem solving: children are divided into groups, discussing, for example, a butterfly, a bird and so on, drawing them in the process of discussion, and placing them on the "decision tree" and explaining their choices.

The method of multichannel activity is the method of working with children, including various analyzers: vision, hearing, touch, taste, smell. For example, when considering a picture, it is recommended to use the following sequence: to choose what is depicted in the picture; to present objects through perceptions by various analyzers. After reviewing all the items shown in the picture, it is necessary to put creative tasks on the children:

- using sounds through"listening" (headphones);

-conduct virtual conversations on behalf of the described characters;

-feel the "aroma" of the flowers depicted in the picture;

- "get out of the picture";

-mentally touch the picture, determine its surface (hot, cold), weather (windy, rainy, sunny, warm, cold) and so on.

Discussion (discussion) is a method of collective discussion of a complex issue. All participants of the educational process are preparing for the discussion, all children are actively involved.At 
CURRENT RESEARCH JOURNAL OF PEDAGOGICS 2(10): 78-85,

October 2021 DOI: https://doi.org/10.37547/pedagogics-crjp-02-10-15

ISSN 2767-3278

(C)2021 Master Journals

\section{Crossref do: 81 Google}

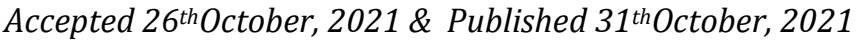

the end of the discussion, a single collective solution of the problem, or recommendation, is formed. Questions (tasks) should not be more than five.When forming them, there must be an opportunity to express different opinions about the problem posed earlier.Children learn to express their thoughts: "I think...", "I believe...", "in my opinion...", "I agree, but...", "because I do not agree...".

Mental attack - this is one of the ways that help develop creativity of children and adultstirishga. This method is convenient when discussing complex problems or issues.Time is given for an individual reflection of the problem (it can even be up to 10 minutes), and after a while additional information about the decision-making is collected. Children who are members of the" attack of the mind " should listen and express all possible (and non-logical) options for solving problems in which they must make the only correct decision.

The quiz is a game of knowledge that answers vocabulary tasks and topics from different fields. Kengaytiradi the development of general knowledge and speech of children. Questions are chosen taking into account the age, program requirements and level of knowledge of the children.

Conversation-communication is a method of dealing with the participation of children. In training with the provision of knowledge, reinforcement of materials, the educator will ask questions to check the understanding of the information provided to the children.

Modeling is a method of interaction of adults and children to solve a problem. The situation is modeled specifically by the educator.

"What? Where is it? When?"- cooperation, creative solution of problems, mutual exchange of views, an active method in which their knowledge and skills and the like prevail.
Pros and cons - a method of working with children, in which children are encouraged to solve the problem from two sides: the pros and cons. For example, there is a task to tell what winter (argument - "for") and why winter (argument - "against") does not like.

Thinking is a method of working with children, in which it is proposed to "guess" possible options for solving the problem.For example, to invite children to call all the autumn months, to talk about what is waiting for each month. Then, instead of a month, introduce yourself and talk about their predictions: "I'm the first month of autumn-September. I'm a very hot month. I love all the children, because they begin to go to school...".The next child continues to talk about this month (work in pairs).

"If so, what would happen... ?- the proposed method of work for children to think and express their assumptions, for example: "what would happen if all the trees on earth were lost?", "What if the wild animals in fairy tales became vegetarians?"and so on.

Imaginary picture-during the process when children are invited to get into a circle , and each child turns describing an imaginary picture (if the first child painted a picture, then he transmits a sheet with a mental picture to another participant of the game, and he continues mental description).

The peculiarity of the game in the quality of the main type of children's activities.

The game is a manifestation of human self, a way of its improvement. Since the game occupies a certain place in adult life, it is of particular importance for children. It was accepted to call him "the companion of childhood". It forms the main content of the life of preschool children. It manifests itself as a leading activity, having an inalienable relationship with Labor and education. Most serious work, in which the child 
CURRENT RESEARCH JOURNAL OF PEDAGOGICS 2(10): 78-85,

October 2021 DOI: https://doi.org/10.37547/pedagogics-crjp-02-10-15

ISSN 2767-3278

(C)2021 Master Journals

\section{Crossref doi) 81 Google}

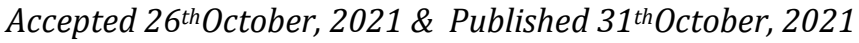

is engaged, is in the form of a game. In the game, all available aspects in the person are activated: the child moves, speaks, perceives, thinks. The game is represented as an important means of upbringing. The game has attracted the attention of educators, psychologists, philosophers, ethnographers, art scientists since ancient times, stands after Labor in the life of society and determines its meaning. Primitive collective tribes reflected in their games hunting, fighting, deforestation. For example, the process of spraying Rice of some tribes of that time was carried out in a very big way with games.

\section{Literature review}

Ya.A.Komensky, K.D.Ushinsky, A.S.Makarenko, P.F. Lestgaf's ideas are also relevant for modern children's game theory. "Children's game has a centuries-old history," K.D.Ushinsky wrote, "a powerful educational tool developed by man himself, and therefore expressing in it the true need of human nature."

Jan Amos Komensky considered the game to be a necessary form of activity of the child, corresponding to his character and inclinations. The game, in his opinion, is a serious mental activity in which all manifestations of the child's abilities develop, the range of ideas about being, the world expands and enriches in the game, speech develops. The child is friends with peers during the game. Ya.A.Komensky considered the game as a cheerful childhood and a condition for the harmonious development of the child, advised adults to take care of children's games, to manage them competently.

P.F.Lestgaft says that children reflect in their games the impressions they receive from the environment. Such activity is of great importance in the development of the child.

Thus, the fact that the game is a social event, that everything around is reflected in the game, has been proved by advanced scientists and teachers through their observations and scientific research.

Educators in the management of children's play should adhere to:

1. establishing the right relationship between play and work

2. to bring up in the game the physical and psychological qualities of children inherent in the future workforce.

\section{AnAlysis AND RESUlts}

Thus, the game is a social activity that arose as a result of labor activity in the process of historical development; the game always reflects real life. Consequently, as social life changes, its content also changes; play is a conscious activity with a specific purpose, which has much in common with work and serves to prepare young people for work. On the basis of play activity, the child develops educational activity, the better the child plays, the better he learns at school.

The first stage of the play activity of young children is an introductory game, which is a subject-subject-game activity. Its content is complex and subtle hand movements.

The next stage is considered a reflection game. This is the highest point in the development of the psychological content of the game of young children. When adults conduct their educational work in a certain sequence, children at this age learn what objects and objects are called, what they are used for, and begin to apply this new knowledge in their game.

Children's play at this age reflects the subject activity of the content.

At the end of the first year and in the game of the children of the second year, the plot is reflected. 
CURRENT RESEARCH JOURNAL OF PEDAGOGICS 2(10): 78-85,

October 2021 DOI: https://doi.org/10.37547/pedagogics-crjp-02-10-15

ISSN 2767-3278

(C)2021 Master Journals

\section{Crossref do) 81 Google}

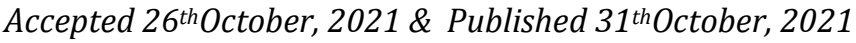

The child ponders with the object in his hand how to use it.The next stage is a story-roleplaying game in which children reflect the familiar work of adults and social relationships of people.Scientific ideas about the gradual development of children's play activity allowed us to develop specific systematic recommendations for the management of children's play activities in various age groups.

\section{Conclusion AND RECommendations}

Thus, the role of the pre-school educational institution in the pedagogical process is very large, and the game is widely used in the upbringing and education of children of preschool age. Because

- the game is an independent activity of children, in which the child's psyche is manifested;

- the game is a form of Organization of the life of children of preschool age;

- the game is one of the means of comprehensive upbringing of children;

- the game is a method and method of teaching and educating children;

- the game is a means of preparing children for educational activities.

Studies of well-known scientists and teachers have shown that through the integrated management of the game, it is possible to influence children with the content of the game, its organization, structure, moral attitudes of children, the level of development of children's play.

Children's play is diverse in its content, nature, and organization.

Creative games are invented by children on their own. There will be no predefined rules in it. The rules of the game are set by children during the game.

The content and rules of the game with the rules are determined by adults. Games with rules include: didactic games, outdoor games, musical games, fun games.

\section{ReFERENCES}

1. Sh.Mirziyoyev. "We will build our great future together with our courageous and noble people." Tashkent - "Uzbekistan"2016.488 p.

2. Sh. Mirziyoyev. "Critical analysis, strict discipline and personal responsibility should be the daily rule of every leader's activity." Tashkent - "Uzbekistan" 2017.104 p.

3. The strategy of actions on the five priority areas of development of the Republic of Uzbekistan for 2017-2021. Decree of the President of the Republic of Uzbekistan No. UP-4947.

4. T. Javliyev. Traditions are a lesson of life. T., "Uzbekistan", 2012.

5. A. Aulonius. Turkish Gulistan or ethics. - T., "Teacher", 2002.

6. Abdulkhayevich, A. A., Yuldashevna, S. Z., \& Abdurashidovna, M. D. (2020). Definition Of The Principles of Teaching Preschool Children. The American Journal of Social Science and Education Innovations, 2(12), 93-99.

7. Mutalova, D. A. (2021). PSYCHOLOGICAL AND PEDAGOGICAL BASES OF THE ORGANIZATION OF THE ECOLOGICAL ENVIRONMENT IN PRESCHOOL. Academic research in educational sciences, 2(2). 
CURRENT RESEARCH JOURNAL OF PEDAGOGICS 2(10): 78-85,

October 2021 DOI: https://doi.org/10.37547/pedagogics-crjp-02-10-15

ISSN 2767-3278

(C)2021 Master Journals

Crossref do) 81 Google

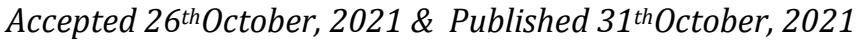

8. Abdurashidovna, M. D. (2020). THE VALUE

OF TEACHING PRESCHOOL CHILDREN

THE SIMPLEST MEASUREMENTS.

Academic research in educational sciences,

(4).

9. Ismatullayeva, N. R. (2021). On the

Introduction of E-Learning Portfolio in the

Educational Process. Current Research

Journal of Pedagogics (2767-3278), 2(09), 35-37.

10. Shomirzayev, M. K. (2021). Developing educational technologiesin school technology education. ASIAN JOURNAL OF MULTIDIMENSIONAL RESEARCH, 10(5), 73-79. 